\title{
Projetos De Aprendizagem Sob As Lentes Da Neurociência Cognitiva: Possibilidade Para A Construção De Conceitos Estatísticos
}

\author{
Learning Projects With The Vision Of Cognitive Neuroscience: Possibility For \\ The Construction Of Statistical Concepts
}

\author{
Suzi Samá* \\ Universidade Federal do Rio Grande - (FURG) \\ Laerte Fonseca $^{* *}$ \\ Instituto Federal de Sergipe - (IF/SP)
}

\begin{abstract}
Resumo
Neste artigo, evidenciamos as descobertas da Neurociência Cognitiva sobre o funcionamento do cérebro no processo de aprendizagem de forma a auxiliar o professor de Estatística no planejamento de estratégias didáticas. Estudos da Neurociência Cognitiva tem demostrado que o estudante aprende aquilo que o emociona, motiva e tem sentido para ele, pois o cérebro seleciona e foca a atenção nas informações mais próximas do que já domina e perde o interesse naquilo que não tem sentido para ele. Desta forma, planejar estratégias didáticas que partam do interesse e contexto do estudante, auxilia no fortalecimento das sinapses da rede neural, e consequentemente, na aprendizagem. Todo o processo investigativo envolvido na realização de um Projeto de Aprendizagem, desde a escolha do tema até a análise dos dados, conduz o estudante a uma atitude mais ativa e promove alterações das relações mantidas pelos neurônios distribuídos por várias áreas do cérebro do estudante, o que interfere nos fatores psicológicos e emocionais e conduz a comportamentos favoráveis ao aprendizado dos conceitos estatísticos.
\end{abstract}

Palavras-chave: Educação Estatística, Neurociência Cognitiva, Projetos de Aprendizagem.

\begin{abstract}
In this paper, we present the findings of Cognitive Neuroscience on the functioning of the brain in the learning process in a way to assist the teacher of Statistics in the planning of didactic strategies. Studies of Cognitive Neuroscience have shown that the students learn what excites, motivates and makes sense to them, because the brain selects and focuses attention on the information that is closest to what them already have and lose interest in what is meaningless for them. In this way, planning didactic strategies that depart from the interest and context of the students, helps in strengthening the synapses of their neural network, and consequently, in their learning. With this understanding, in this paper, we present the methodology of Learning Projects as a possibility for the construction of statistical concepts. The whole investigative process involved in the realization of a Learning Project, from the choice of the

\footnotetext{
* Doutora em Educação em Ciências/FURG. Professora Adjunta da FURG. Rio Grande, RS, Brasil. E-mail: suzisama@furg.br.

** Doutor em Educação Matemática/UNIAN-SP. Professor Titular de Educação Matemática/IF, Aracaju, SE, Brasil. E-mail: laerte.fonseca@uol.com.br.
} 
subject to the analysis of the data, leads the students to a more active attitude and promotes changes in the relations maintained by the neurons distributed in various areas of the students' brains, which interferes in psychological and emotional factors and leads to favorable behaviors to the learning of statistical concepts.

Keywords: Statistics Education, Cognitive Neuroscience, Learning Projects.

\section{Introdução}

Muitas vezes nos questionamos por que alguns estudantes aprendem Estatística e outros não. Se a forma como ensinamos é a mesma, não deveriam todos aprender? Talvez aí resida o equívoco: a padronização na forma de ensinar, como se todos os estudantes fossem iguais. $\mathrm{Na}$ busca por lançar luz ao desafio que envolve os processos do ensinar e o aprender Estatística, procuramos, neste artigo, apresentar o planejamento e desenvolvimento de uma estratégia didática que considera a forma como o cérebro recebe e processa a informação.

O cérebro é constituído por dezenas de bilhões de células nervosas, os neurônios, os quais comunicam-se entre si por meio das sinapses. A aprendizagem, do ponto de vista neurobiológico, consiste na formação e consolidação das ligações sinápticas entre os neurônios. A cada nova vivência ou experiência do indivíduo novas conexões neurais são produzidas, o que torna a aprendizagem um fenômeno individual que obedece às circunstâncias históricas de cada um. (Cosenza \& Guerra, 2011; Relvas 2012).

De acordo com Maturana e Varela (2005), o aprender pode ser entendido como um processo de adaptação, uma vez que o conhecimento ocorre pela interação entre o estudante e o meio (o que, no meio educacional, contempla o professor, a escola, outros colegas, etc.). Assim, toda mudança depende da estrutura inicial de cada estudante, bem como da dinâmica de interação entre este e o meio, das circunstâncias em que se encontra inserido e que modifica o fluir de suas emoções (Maturana \& Varela, 2005).

O conhecimento deriva das interações recorrentes e do estado emocional em que nos encontramos, pois é a emoção que nos conduz à ação (Maturana, 2002). Esta constatação evidencia que o envolvimento emocional é pressuposto para a aprendizagem. Desta forma, o estudante aprende o que o motiva, emociona e deseja, ou seja, aquilo que tem significado para seu cotidiano (Relvas, 2009, 2012).

Pensar em estratégias didáticas que possibilitem tornar os conceitos relevantes para o aprendiz é um dos desafios do ser professor. Uma das vias para efetivar tal reflexão, segundo Bortoli e Teruya (2017), é considerar os estudos da Neurociência Cognitiva, os quais podem 
contribuir na elaboração de estratégias didáticas fundamentadas na neurobiologia do aprendizado. Apesar de os referidos estudos revelarem dados sobre o funcionamento do cérebro em situações de aprendizagem, a maioria dos professores ainda desconhecem estas formas de aprender (Fagundes, 2004).

Cabe ressaltar que as pesquisas em Neurociência Cognitiva por si só não resolverão os problemas educacionais, ainda que forneçam subsídios para fundamentar estratégias didáticas que se têm revelado um sucesso (Cosenza \& Guerra, 2011), como, por exemplo, a metodologia dos Projetos de Aprendizagem. Ressaltamos tal metodologia, pois esta ocorre a partir de um tema de interesse dos estudantes e abrange a interação em seu desenvolvimento, os quais se configuram como pressupostos para a construção do conhecimento.

Com este entendimento, neste artigo, apresentamos os Projetos de Aprendizagem na construção dos conceitos estatísticos, fundamentados na Neurociência Cognitiva. Na próxima seção, abordamos a contribuição da Neurociência Cognitiva na Educação; na sequência, contextualizamos a metodologia de Projetos de Aprendizagem na construção dos conceitos estatísticos pelo estudante; na última seção, discorremos sobre o desenvolvimento dos Projetos de Aprendizagem na sala de aula de Estatística à luz da Neurociência Cognitiva; e, por fim, tecemos algumas considerações.

\section{Neurociência Cognitiva E Educação}

Um aprendiz, ainda que tenha todas as suas funções cognitivas preservadas e sem alteração estrutural ou funcional do sistema nervoso, pode apresentar dificuldades para aprender. Apesar de a aprendizagem ocorrer no cérebro, esta depende da interação do indivíduo com o meio, de modo que problemas na aprendizagem podem estar relacionados a diversos aspectos relativos tanto ao indivíduo, quanto ao meio ou a ambos (Cosenza \& Guerra, 2011). Assim, torna-se premente voltar nosso olhar para o ambiente educacional, pois o meio com o qual interagimos “influencia o processo de aprendizagem, interferindo nos fatores psicológicos e emocionais e induzindo comportamentos que podem ser mais ou menos favoráveis ao aprendizado" (Cosenza \& Guerra, 201, p. 130).

A aprendizagem diz respeito ao processo pelo qual o conhecimento é adquirido e/ou modificado (Rodrigues, 2016). Este processo de aquisição "tem início na estimulação sensorial e termina com o seu armazenamento e recuperação (memória), através da representação interna que criamos das informações recebidas" (Rodrigues, 2016, p.3). Segundo Metring (2011), "a 
rede neuronal é que determina a capacidade de armazenamento e evocação de dados, sem os quais não podemos pensar em memória, e, portanto, não haverá aprendizagem” (p. 98).

Deste modo, a aprendizagem ocorre devido à plasticidade das redes neurais que se autoorganizam, em contínua mudança estrutural, em função de estímulos externos (por meio dos sentidos) e internos (por meio, por exemplo, da memória). No entanto, nada externo ao aluno pode determinar sua aprendizagem, mas sim desencadeá-la como um agente perturbador (Maturana e Varela, 2005). Neste sentido, configuram-se como agentes perturbadores o professor, as estratégias didáticas, os colegas de aula e os demais elementos do ambiente de aprendizagem.

Estas perturbações podem desencadear diferentes mudanças estruturais em cada estudante, tendo em vista que "a história de vida de cada um constrói, desfaz e reorganiza permanentemente as conexões sinápticas entre os bilhões de neurônios que constituem o cérebro" (Cosenza \& Guerra, 2011, p. 28). Os autores defendem que estratégias didáticas que façam uso de recursos multissensoriais podem estimular a ativação de múltiplas redes neurais com associações entre si.

Por esse motivo, ambientes de aprendizagem mais diversificados, nos quais os estudantes sejam constantemente desafiados a pensar, criar e realizar, podem desenvolver novos conhecimentos ou comportamentos que possibilitem a estes transformar sua prática e o mundo em que vivem. Os novos comportamentos advêm do conjunto de células nervosas ou redes neurais que constituem o sistema nervoso e são adquiridos pelo processo de aprendizagem. Este, por sua vez, requer várias funções cognitivas, como emoção, memória, atenção, percepção, e, portanto, depende do cérebro (Guerra, 2011).

Os estudos sobre o cérebro apontam que as emoções contribuem para a aprendizagem porque auxiliam a passagem da memória de curto para a memória de longo prazo, assim como a motivação é indispensável para a liberação de substância responsável por mobilizar a atenção e reforçá-la na relação com o objeto que a afetou. (Bortoli \& Teruya, 2017, p. 70)

Conforme Agüera (2008), as vivências que vierem acompanhadas de fortes emoções serão melhor recuperadas no futuro. Consequentemente, o desencadeamento de emoções favorece o estabelecimento de memórias e, por isso, podemos dizer que são as emoções que orientam a aprendizagem, ou seja, aprendemos aquilo que nos emociona. Este comportamento está relacionado a diferentes domínios de ações, nos quais nos movemos. O emocionar, por sua vez, corresponde ao fluxo de um domínio de ações a outro, na dinâmica do viver (Maturana, 
2002).

Toda informação que será decodificada, processada e armazenada no córtex passa antes pelo sistema límbico, gerador das emoções. As conexões emocionais do sistema límbico provocam a liberação de neurotransmissores relacionados, tanto ao prazer/satisfação, que facilitam a aprendizagem, quanto ao desprazer, os quais bloqueiam a aprendizagem. Desta forma, quanto mais prazerosa for a atividade pedagógica proposta pelo professor, mais fácil a internalização do conteúdo pelo estudante (Metring, 2011).

O cérebro seleciona e foca a atenção nas informações mais relevantes para nossa sobrevivência. Consequentemente, "aprendemos o que é significativo e necessário para vivermos e esquecemos aquilo que não tem mais relevância para o nosso viver" (Guerra, 2011, p. 6). No contexto educacional, a palavra atenção é cotidianamente utilizada, no entanto, "poucos sabem das limitações dos processos mentais envolvidos no ato de focalizar a atenção e como o conhecimento dessas podem contribuir para melhorar o desempenho dos estudantes" (Silva, 2018). A atenção é um aspecto fundamental para a aprendizagem, uma vez que esta função cognitiva é responsável por selecionar um número limitado de estímulos, oriundos do meio externo ou produzidos no interior do indivíduo, permitindo um uso mais eficiente da capacidade limitada de processamento do cérebro.

A atenção é mobilizada pelos esquemas mentais que já temos em nossos arquivos cerebrais. Por isto, uma das estratégias que o professor pode adotar para atrair a atenção dos estudantes é a realização de uma exposição prévia dos conceitos a serem aprendidos, estabelecendo ligações com o cotidiano dos estudantes (Cosenza \& Guerra, 2011). Isso porque “dificilmente um aluno prestará atenção em informações que não tenham relação com o seu arquivo de experiências, com seu cotidiano ou que não sejam significativas para ele" (Guerra, 2011, p. 6). Assim, o planejamento e a organização do ambiente educacional podem direcionar o foco atencional para os aspectos específicos dos conteúdos trabalhados na disciplina. Para Maio (2015, p. 103), “[...] somente aqueles registros, estímulos, que despertam a nossa atenção, interesse ou por repetição, são transferidos para regiões específicas no cérebro, chamadas de memórias sensórias de curta duração e esse controle é feito pelo sistema límbico que também é responsável pelas emoções".

Neste sentido, a diversidade de estratégias didáticas multissensoriais, bem como o estabelecimento de relações contextuais com os conceitos, em nosso caso os conceitos estatísticos, mobilizam os processos atencionais, uma vez que proporcionam uma exploração mais intensa da nossa capacidade de lidar com as informações e aprender (Cosenza \& Guerra, 
2011). Com este entendimento, apresentamos a metodologia de Projetos de Aprendizagem como uma estratégia didática vinculada à emoção, para auxiliar o estudante a compreender os conceitos estatísticos.

\section{Projetos De Aprendizagem Na Construção Dos Conceitos Estatísticos}

A elaboração de um projeto constitui a etapa fundamental de toda pesquisa que pode ser conduzida a partir de um conjunto de interrogações, quer sobre a temática a ser investigada, quer sobre o mundo à nossa volta (Fagundes, Sato \& Maçada-Laurino, 1999). Conceber e realizar um projeto implica esforço e envolvimento pessoal, bem como capacidade de gerir a complexidade das situações que emergem no processo, o que se torna um desafio o qual pode ser muito estimulante para os estudantes dispostos a assumir um papel ativo no próprio processo de aprendizagem (Prado, 2006).

No contexto da Educação Estatística, atividades investigativas no processo de ensino e aprendizagem têm sido defendidas por pesquisadores da área. Estas têm recebido diferentes nomenclaturas como Ciclos Investigativos (Wild \& Pfannkuch, 1999; Cazorla, Silva \& Santana, 2018), Modelagem Matemática (Campos, Wodewotzki \& Jacobini, 2011; Souza, Souza, Mendonça \& Lopes, 2013) e Projetos de Aprendizagem (Porciúnucla e Samá, 2014, 2015).

Todas defendem basicamente os mesmos princípios; para os pesquisadores, participar do planejamento de uma atividade de investigação, desde a escolha de um tema até a análise dos dados, possibilita aos estudantes apropriarem-se dos procedimentos estatísticos na esfera de um contexto que faça sentido e tenha significado para eles. Os pesquisadores destacam que, neste processo investigativo, a ação e reflexão são estimuladas e contribuem para o desenvolvimento do letramento, raciocínio e pensamento estatístico.

Nos Projetos de Aprendizagem, a questão a ser pesquisada parte da curiosidade, das dúvidas, das indagações do estudante, não sendo impostas pelo professor. Segundo Silva, Menezes e Fagundes (2017), é a partir de seu conhecimento prévio, que o aprendiz vai se movimentar, interagir com o desconhecido, ou com novas situações, para se apropriar do conhecimento específico, "fazendo com que os processos socioafetivos e a conscientização sejam ampliados" (p. 30).

Quando o aprendiz é desafiado a questionar, quando ele se perturba e necessita pensar para expressar suas dúvidas, quando lhe é permitido formular questões que tenham significação para ele, emergindo de sua história de vida, de seus interesses, seus valores e condições pessoais, passa a desenvolver a competência para formular e equacionar problemas. Quem consegue formular com clareza um problema, a ser resolvido, começa 
a aprender a definir as direções de sua atividade (Fagundes, et al., 1999, p. 16).

Na formulação do problema e na escolha do tema a ser investigado, surgem dúvidas que produzem perturbações no sistema de significação dos estudantes, levando-os a buscar respostas, a fim de saber mais sobre o assunto. Neste processo de busca, as informações levantadas sobre o tema tanto poderão sanar as dúvidas quanto refutar algumas das certezas iniciais. Para Porciúncula e Samá (2014) e Fagundes et al. (1999), as certezas para as quais não se conhece os fundamentos que as sustentem são denominadas de provisórias e as dúvidas são sempre temporárias, de modo que o processo de investigação consiste no esclarecimento das dúvidas e na validação das certezas.

Um Projeto de Aprendizagem se desenvolve de forma colaborativa e cooperativa, em constante negociação com o professor. Para que tal colaboração e cooperação se efetivem, o docente precisa estar preparado a desenvolver esta proposta em sala de aula. Para Lopes e Mendonça (2015), a falta de clareza sobre os aspectos inerentes a uma abordagem investigativa inibe muitos professores a adotarem este método de ensino em sua prática. Por este motivo, entendemos que o desenvolvimento de atividades desta natureza, tanto na formação inicial quanto continuada, pode fornecer subsídios para que o professor promova tal potencial pedagógico em sua prática.

Alguns professores têm desenvolvido tal perspectiva em sua prática pedagógica e refletido acerca desta em suas pesquisas. Destacamos o trabalho de Silva et al. (2017), que apresenta experiência com esta metodologia na disciplina de Projetos de Aprendizagem em Ambientes Digitais oferecida, em caráter eletivo, a estudantes de licenciatura dos cursos de Matemática, Física Química, Letras e Ciências Sociais da Universidade Federal do Rio Grande do Sul. Esta disciplina, ministrada em 2015, foi organizada em um site, onde foram disponibilizados materiais de apoio, sugestões de leitura sobre a metodologia de Projetos de Aprendizagem e espaço para o registro de interações e produções individuais dos licenciandos.

Segundo os autores, apesar da disciplina já estar na fase final dos cursos de licenciatura, para muitos estudantes, este foi o primeiro contato com a metodologia de Projetos de Aprendizagem. Tal observação demonstra a lacuna ainda existente nos cursos de formação inicial de professores, em especial no que diz respeito a metodologias de ensino. Na visão dos futuros professores, que participaram da disciplina, a metodologia de Projetos de Aprendizagem contribuiu para o "envolvimento nas atividades e discussões em sala de aula, possibilitando uma aprendizagem diferente de simplesmente recorrer à leitura e sistematização de conteúdo" (p. 35). 
Samá e Porciúncula $(2014,2017)$ analisaram a opinião dos estudantes de graduação, de cursos da área de Ciências Sociais, em relação ao uso da metodologia de Projetos de Aprendizagem no ensino de Estatística, por meio de um questionário. De acordo com as pesquisadoras, esta abordagem foi adotada como uma alternativa para superar uma visão empirista em detrimento de uma perspectiva construtivista. Enquanto a primeira, que tem prevalecido nas aulas de Estatística, enfatiza na aplicação de fórmulas e resolução de cálculos, a segunda foca na solução de problemas e prima pela interatividade, autonomia e análise crítica no ambiente educacional.

Nas respostas dos estudantes ao questionário de avaliação da proposta pedagógica adotada na disciplina, a elaboração de uma pesquisa quantitativa promoveu a percepção dos estudantes acerca da sistemática que a permeia, uma vez que possibilitou que estes se deparassem com situações ainda não cogitadas. Tal processo tornou os conceitos estatísticos abordados em sala de aula mais significativos e mais próximos do contexto do estudante.

Em ambas as pesquisas, os estudantes destacaram que a interação entre os colegas e a troca de informações facilitaram o entendimento de alguns conceitos e possibilitaram sanar dúvidas, o que, consequentemente, possibilitou maior aprendizado (Porciúncula \& Samá, 2014; Silva et al., 2017). Para Garfield (2013), o trabalho cooperativo no ensino de Estatística melhora a habilidade de comunicação entre os estudantes, a capacidade de trabalhar em equipe, bem como possibilita ao aluno reestruturar os novos conceitos estatísticos, adicionando-os à própria estrutura cognitiva.

O fundamento da prática pedagógica se altera quando da realização dos Projetos de Aprendizagem: passa de um modelo de aula expositiva, arraigado na prática tradicional, para um modelo pedagógico relacional, baseado na concepção interacionista/construtivista, no qual o estudante é protagonista no processo de aprendizagem, pois esta ocorre a partir da ação e problematização do aluno (Becker, 2012). Neste modelo pedagógico, “o contexto do estudante é um balizador das estratégias de ação do professor, o qual tem que, continuamente, reelaborar suas intervenções" (Samá \& Porciúncula, 2017, p. 5).

Este processo investigativo proporciona ao estudante pensar, refletir, criar com autonomia a solução de problemas em diferentes contextos. Nos Projetos de Aprendizagem, a avaliação é contínua ao longo de todo o desenvolvimento da pesquisa, desde a coleta de informações, que validam/refutam as certezas e dúvidas dos estudantes sobre o tema a ser investigado, até o momento em que o resultado da pesquisa é discutido e socializado com os demais grupos da turma. 
No Ensino de Estatística, por sua vez, a metodologia de Projetos de Aprendizagem assume um caráter peculiar, uma vez que oportuniza aplicar os conceitos estatísticos no planejamento e desenvolvimento das etapas da pesquisa, processo que será abordado na próxima seção à luz das contribuições da Neurociência Cognitiva.

\section{Desenvolvimento Dos Projetos De Aprendizagem Na Construção Dos Conceitos Estatísticos Sob As Lentes Da Neurociência Cognitiva}

Estudos da Neurociência Cognitiva têm demostrado que as sinapses se fortalecem à medida que a informação seja significante para a rede neural do estudante (Metring, 2011). Em outras palavras, dificilmente ocorrerá a aprendizagem apenas submetendo o estudante a uma expressiva quantidade de conteúdo desprovida de sentido para ele. Desta forma, planejar estratégias de ensino que possam aproximar os conteúdos abordados em sala de aula do contexto dos estudantes é uma possibilidade para o aprofundamento dos conceitos estatísticos e para o desenvolvimento cognitivo, afetivo e social dos alunos.

Na metodologia dos Projetos de Aprendizagem esta aproximação se efetiva, pois, inicialmente, os estudantes já são instigados a escolher o tema de interesse, para posterior debate com os colegas. Tal escolha possibilita que o aluno concentre sua atenção na atividade proposta em razão de sua significância, mobilizando a emoção. Para Fonseca et al (2017), a função cognitiva atenção deve ser conquistada no início da atividade, pois a nível neuropsicológico, o cérebro perde o interesse naquilo que não tem sentido para ele, bem como recebe melhor aquilo que está mais próximo do que já domina.

Em um Projeto de Aprendizagem, o estudante assume, mobilizado pela emoção, uma atitude ativa diante do conhecimento. Esta atitude, por sua vez, desencadeia a motivação, também indispensável no processo de aprendizagem. Enquanto a emoção auxilia no registro das informações na memória de longo prazo, a motivação, com a liberação de uma substância denominada dopamina, ativa a região do bem-estar no cérebro, estimulando o estudante a focar a atenção na atividade proposta (Izquierdo, 2006).

Ao longo do debate sobre os temas, em que cada estudante explica sua escolha e curiosidade sobre o mesmo, alguns desistem de suas propostas e adotam o tema de outro colega, por considerarem este mais interessante e instigante, de modo que os grupos começam a ser formados. Escolhidos os temas e definidos os grupos, os estudantes formulam as dúvidas 
temporárias e as certezas provisórias que têm sobre o assunto. Esta busca pela formulação das dúvidas e certezas intensificam as emoções e a atividade cerebral dos estudantes, produzindo vários neurotransmissores e estimulando novas sinapses que conduzem à aprendizagem. “Quando o estímulo já é conhecido do sistema nervoso central, desencadeia uma lembrança; quando o estímulo é novo, desencadeia uma mudança.” (Relvas, 2012, p. 55).

A partir da busca de informações sobre o tema escolhido, de forma a refutar e/ou validar as dúvidas e certezas, o Projeto de Aprendizagem vai sendo delineado. Estas informações podem ser encontradas em diversos materiais, como artigos científicos, sites da internet e livros. Os materiais vão sendo armazenados no ambiente virtual da disciplina, em um blog, ou outro recurso digital que possibilite o compartilhamento de arquivos e informações, formando um repositório de aprendizagem, que pode ser acessado por todos do grupo.

O compartilhamento de informações sobre o tema e a interação entre os estudantes possibilita refletir e reformular o planejamento do Projeto de Aprendizagem (Silva et al, 2017). Segundo Bortoli e Teruya (2017), “a interação permite o aumento das ligações entre os neurônios, e consequentemente, a formação de novos circuitos e a geração de um novo conhecimento" (p. 74). Este, por sua vez, conforme Maturana (2006), é adquirido na convivência em um certo espaço, que pode ser a escola ou a universidade.

A partir das aprendizagens construídas no convívio com os colegas e no processo de coleta e elaboração das informações, os estudantes já podem iniciar a escrita da pesquisa, organizando a introdução e uma breve revisão da literatura, o que possibilita a construção de novos conhecimentos sobre o tema escolhido. A pesquisa auxilia na elaboração de um instrumento de coleta de dados, o qual precisa conter questões sobre o perfil dos respondestes e sobre o tema investigado. Na elaboração do instrumento de coleta de dados, o professor apresenta ou retoma conceitos estatísticos necessários para a realização da pesquisa, como os tipos de variáveis qualitativas (cor predileta, sexo, nível de escolaridade, ...) e quantitativas (altura, salário, preço de produtos, ...), fase esta em que a Estatística se faz proeminente. Um instrumento com diferentes tipos de variáveis possibilita que o professor discuta a forma de representação e a melhor medida estatística para cada uma.

Elaborado o instrumento de coleta de dados, o professor já pode ir apresentando os conceitos de população e métodos de amostragem. Definida a amostra, os alunos iniciam o processo de coleta de dados, os quais serão posteriormente digitados em uma planilha eletrônica. Os estudantes também podem optar por elaborar o instrumento de coleta de dados 
em questionário on-line, como o Google Forms. Depois dos dados coletados e organizados em uma planilha, os estudantes escolhem, com o auxílio do professor, a forma de apresentar e resumir (tabelas, gráficos e medidas estatísticas) os dados.

$\mathrm{Na}$ organização e apresentação dos dados, os estudantes organizam os resultados em tabelas, gráficos e medidas estatísticas, como média, mediana e desvio-padrão relacionando estes conceitos com as questões levantadas a partir do tema sob investigação. No entanto, em geral, os estudantes têm dificuldade nesta etapa do processo, tendo em vista o escasso conhecimento sobre os conceitos de Estatística pouco abordados no Ensino Fundamental e Médio. Assim, conforme Maio (2015), o cérebro não consegue gerar sinapses e associar os novos registros a registros sensoriais anteriores ou a registros bem conhecidos e gravados na memória de longo prazo.

Tal situação demanda que o professor dedique tempo das aulas para auxiliar os estudantes a compreender de que forma as tabelas e gráficos são construídos, bem como podem facilitar a visualização da informação. As tabelas estatísticas são um suporte usado na apresentação de dados empíricos em forma de grades, evidenciando relações entre as diferentes entradas da tabela (valores das frequências absolutas ou percentuais das variáveis), a fim de que o estudante ou leitor da informação obtenham alguma conclusão a partir dos dados (Ortiz de Haro, 2002).

Outra forma de comunicar a informação é por meio da representação gráfica, a qual, segundo Silva e Samá (2018), permite sintetizar a informação de modo mais atraente, dinâmico e compreensível ao leitor, evocando a atenção deste. Esta função cognitiva tem um papel importante na leitura e na compreensão dos gráficos. Conforme Peirce (2005), a atenção afeta fortemente a memória por três motivos: um pensamento será recordado por mais tempo quanto maior a atenção que a ele se prestou; quanto maior a atenção, mais estreita será a conexão e mais acurada a sequência lógica do pensamento; e, através da atenção, pode-se recuperar um pensamento ou lembrança que tenha sido esquecido.

O processamento de informações apresentadas em gráficos depende do conhecimento que o estudante ou o leitor da informação possui a respeito desses na memória de longo prazo. A escolha do melhor gráfico para representar um determinado conjunto de dados se vincula ao reconhecimento dos elementos que o constituem e das suas inter-relações. Sem o acesso a esse conhecimento, o estudante terá dificuldade, por exemplo, em associar os pontos nos eixos ou comparar áreas de dois setores circulares, o que poderá ser um obstáculo na compreensão da 
informação (Silva \& Samá, 2016). O fato da informação gráfica ser, predominantemente, visual "[...] permite uma leitura mais rápida e compreensão mais imediata por parte dos leitores" (Kanno, 2013, p.11). Para o autor, por meio dos gráficos, o leitor pode identificar semelhanças, diferenças e proporções, bem como comparar de imediato as grandezas em questão. A associação destes recursos visuais com o texto verbal auxilia na compreensão da informação divulgada.

A inter-relação entre os conceitos estatísticos auxilia na escolha das medidas estatísticas utilizadas para resumir a informação sobre os dados coletados, bem como destaca a complexidade das possibilidades de interpretação sobre a temática investigada no Projeto de Aprendizagem e o conhecimento que o aluno pode alcançar. Para Metring (2011) "uma boa rede neural não necessariamente se forma pelo acúmulo de conteúdo, mas sim pela capacidade crítica da pessoa em descobrir se a solução encontrada foi adequada (p. 98).

Além disso, o contexto em que a investigação é realizada, por meio dos Projetos de Aprendizagem, permite ao aluno contemplar diretamente em que aspecto de sua realidade os conceitos estatísticos, vistos em sala de aula, podem ser aplicados. Para Cosenza e Guerra (2011) “o cérebro tem uma motivação intrínseca para aprender, mas só está disposto a fazê-lo para aquilo que reconheça como significante" (p. 48). Desta forma, fica evidente o papel da Estatística na tomada de decisão frente a problemas presentes no contexto de vida de cada um. Segundo Bartoszeck e Bittencourt (2017), o processo de contextualização do conhecimento favorece que as novas informações possam se ancorar nas vivências anteriores retidas na memória.

Para fazer uma escolha ou para tomar uma decisão, é necessário ser capaz de contrastar os estímulos percebidos na situação atual com os padrões armazenados na memória em razão das experiências anteriores. A memória fornece a capacidade de retenção de vivências. Sem memória não existiria a capacidade de classificar as experiências, nem a possibilidade de compará-las para estabelecer analogias e diferenças entre a situação atual e as situações já vividas. (Agüera, 2008, p. 43).

Ensinar Estatística por meio dos Projetos de Aprendizagem se insere nesta proposta de relacionar os conteúdos a serem aprendidos com as experiências vivenciadas anteriormente. A complexidade do processo investigativo demanda, por parte do professor, uma habilidade para mediar a realização de uma pesquisa, pois, além de ter que possuir um conhecimento estatístico básico sobre os conceitos, também é exigida a compreensão das relações entre as variáveis e a leitura e interpretação dos dados. 
Ao adotar tal metodologia, o professor precisa estar ciente das incertezas inerentes a um processo investigativo, o que exige flexibilidade e abertura para compartilhar decisões com os estudantes, de modo que muitos aspectos escapam ao planejamento prévio e precisam ser repensados ao longo da disciplina. Segundo Maturana (1993) é nessa convivência, que ambos, professores e estudante, irão transformar-se. Este processo interativo, mediado pelo professor, deve ser permanente, no sentido de que, muitas vezes, "os estudantes tendem a ignorar as evidências dos dados e tirar conclusões, ainda, pautados nas suas crenças, sem levar em consideração o que as tabelas, gráficos e medidas sinalizam sobre o comportamento das variáveis em estudo" (Cazorla et al., 2018, p. 371).

Dependendo do nível de ensino e dos conteúdos previstos na disciplina, o processo de análise pode incluir testes estatísticos que possibilitem confirmar ou refutar hipóteses e testar a associação entre variáveis. Por fim, os estudantes apresentam os resultados e conclusões de sua pesquisa aos demais colegas da turma. Esta socialização se configura em um momento rico de aprendizagens em que os estudantes podem relatar as experiências e dificuldades, bem como alguns equívocos cometidos ao longo do processo investigativo.

De acordo com Maturana e Varela (2005), nossas experiências e a interpretação que fazemos a partir delas dependem de nossa estrutura interna. Para os autores, o aprender está relacionado com as mudanças estruturais que ocorrem em nós de maneira coerente com a história de nossas interações recorrentes com o meio.

\section{Considerações}

No presente artigo, buscamos evidenciar as descobertas da Neurociência Cognitiva sobre o funcionamento do cérebro no processo de aprendizagem de forma a auxiliar o professor de Estatística no planejamento de suas aulas e estratégias didáticas. Planejar estas estratégias, considerando que o estudante aprende o que o motiva, emociona e tem significado para seu cotidiano, auxilia no fortalecimento das sinapses da rede neural, e consequentemente, na aprendizagem.

Neste sentido, a possibilidade de o estudante escolher uma temática pela qual tem interesse ou curiosidade mobiliza os esquemas mentais que este já possui. A inter-relação entre os conceitos estatísticos com o contexto de vida do estudante, a escolha da medida estatística que melhor resume a informação, a identificação do gráfico mais adequado para a variável em análise, evidenciam o conhecimento que o aluno pode alcançar ao longo do processo 
investigativo inerente a metodologia de Projetos de Aprendizagem.

Desta forma, a metodologia de Projetos de Aprendizagem, apresentada aqui como uma alternativa para o ensino dos conceitos estatísticos, permite ao professor desencadear funções cognitivas que favorecem a aprendizagem. Pensar e refletir, tanto sobre o tema investigado quanto sobre os conceitos estatísticos envolvidos na realização da pesquisa, promove mudanças na estrutura dos estudantes, o que conduz a comportamentos favoráveis ao aprendizado.

Esperamos que este artigo inspire outros docentes a planejar e desenvolver estratégias didáticas considerando os fundamentos e contribuições da Neurociência Cognitiva no processo de aprendizagem dos conceitos estatísticos.

\section{Agradecimentos}

O presente trabalho foi realizado com apoio da Coordenação de Aperfeiçoamento de Pessoal de Nível Superior (CAPES) no Estágio Pós-Doutoral, Brasil.

\section{Referências}

Bartoszeck, A. B.; Bittencourt, D. F. (2017). Alfabetização em Neurociência e Educação para Professores do Ensino Fundamental e Médio: um estudo exploratório.Revista Paidéi@. Unimes Virtual. v.9, n.15, jan. Recuperado de: $<\mathrm{http}$ :/periodicosunimes.unimesvirtual.com.br/index.php?journal=paideia\&page=index $>$

Becker, F. (2008). A Epistemologia do Professor: o cotidiano da escola. $13^{\mathrm{a}}$ ed. Petrópolis, RJ: Vozes.

Becker, F. (2012). Educação e Construção do conhecimento. 2. ed. Porto Alegre, RS: Penso Editora Ltda, 2012.

Bortoli, B.; Teruya, T. K. (2017). Neurociência e Educação: Os Percalços e possibilidades de um caminho em construção. Imagens da Educação, 7(1), 70-77.

Cazorla, I. M.; Silva, A. V.; Santana, E. R. S. (2018). Reflexões sobre o ensino de variáveis conceituais na Educação Básica. REnCiMa, 9(2), 354-373.

Cosenza, R., Guerra, L. (2011). Neurociência e educação: como o cérebro aprende. Porto Alegre: Artmed.

Fagundes, L. C. (2004). [O professor deve tornar-se um construtor de inovações]. Entrevista concedida a Midiativa - Centro Brasileiro de Midia para Crianças e Adolescentes. Disponível em: <http://www.midiativa.tv/index.php/educadores/content/view/full/1053/>. Acesso em: setembro de 2011.

Fagundes, L. C.; Sato, L. S.; Laurino, D. P. (1999). Aprendizes do futuro: as inovações 
começaram! Brasília: Secretaria da Educação a Distância, Ministério da Educação. Disponível em: < http://pa2009b2.pbworks.com/f/aprender.pdf>. Acesso em: 20 jun. 2018.

Fonseca, L.; Samá, S.; Soares, K.; Pontes, L. (2017). Uma ecologia dos mecanismos atencionais fundados na neurociência cognitiva para o ensino de matemática no século XXI. Caminhos da Educação Matemática em Revista. 1 (X), 19-30.

Garfield, J. (2013). Cooperative Learning Revisited: From an Instructional Method to a Way of Life. Journal of Statistics Education. 21(2), 1-9.

Guerra, L. B. (2011). O diálogo entre a neurociência e a educação: da euforia aos desafios e possibilidades. Revista Interlocução, 4, 3-12.

Izquierdo, I. (2006). Memória. Porto Alegre : Artmed.

Kanno, M. (2013). Infografe: Como e porque usar infográficos para criar visualizações e comunicar de forma imediata e eficiente. São Paulo: Edição eletrônica.

Mendonça, L. O.; Lopes, C. E. (2015). Planejamento de Atividades de Modelagem Matemática: um caminho possível. EM TEIA - Revista de Educação Matemática e Tecnológica Iberoamericana, 6(1), 1-24.

Markova, D. (2000). O natural é ser inteligente. São Paulo: Summus.

Maturana, H. (1993). Uma Nova Concepção de Aprendizagem. Revista Dois Pontos: Ed. UFMG, Belo Horizonte, 2(15), 28-35, out./inv.

Maturana, H. (2002). Emoções e linguagem na educação e na política. Belo Horizonte: Editora UFMG.

Maturana, H. (2006). Cognição, ciência e vida cotidiana. Belo Horizonte: Ed. UFMG.

Maturana, H. R.; Varela, F. (2005). A árvore do conhecimento: as bases biológicas da compreensão humana. 5a ed. São Paulo: Palas Athena.

Metring, R. A. (2011). Neuropsicologia e aprendizagem: fundamentos necessários para planejamento do ensino. Rio de Janeiro: Wak Editora.

Ortiz de Haro, J.J. (2002). La probabilidad en los libros de texto. (Tese de doutorado). Universidad de Granada, Departamento de Didáctica de la Matemática.

Peirce, C.S. (2005). The Collected Papers of Charles Sanders Peirce. Semiótica: Charles S. Peirce (1839-1914). São Paulo: Perspectiva, p. 341.

Porciúncula, M.; Samá, S. P. (2014). Teaching Statistics Through Learning Projects. Statistics Education Research Journal, 13, 177 - 186.

Porciúncula, M.; Samá, S. P. (2015). Projetos de Aprendizagem. In: Porciúnucla, M.; Samá, S. P. (Org). Educação Estatística: Ações e estratégias pedagógicas no Ensino Básico e Superior. Curitiba: CRV, pp. 133-141.

Prado, M. E. B. B. (2006). A mediação pedagógica: suas relações e interdependências. In Anais 
do $17^{\circ}$ Simpósio Brasileiro de Informática na Educação. Brasília, DF.

Relvas, M. P. (2012). Neurociência na Prática Pedagógica. Rio de Janeiro: Wak Editora.

Rodrigues, P. F. S. (2016). Processos Cognitivos Visuoespaciais e Ambiente Visual Circundante: Implicações Educacionais. Psicologia: Teoria e Pesquisa. 32(4), 1-10.

Samá, S. P.; Porciúncula, M. (2017). Percepção dos Estudantes em Relação ao Ensino de Estatística Fundamentado no Modelo Pedagógico Relacional. In Anais do $20^{\circ}$ ENFOPE, $11^{\circ} \quad$ FOPI. Aracaju, SE. Recuperado de $<$ https://eventos.set.edu.br/index.php/enfope/article/view File/5029/1487>. Acesso em: 25 jun. 2018.

Silva, P. F.; Menezes, C. S.; Fagundes, L. C. (2017). Avaliação processual no Contexto de Projetos de Aprendizagem. Informática na Educação: teoria \& prática. Porto Alegre, v.20, n.1, jan./abr.

Silva, C. R.; Samá, S. P. (2016). Percepções de estudantes do ensino superior sobre a infografia na divulgação da informação. Educ. Matem. Pesq., São Paulo, 18(3), 1429-1447.

Silva, C. R.; Samá, S. P. (2018). Infografia com Gráficos: um estudo semiótico da percepção e do processamento da informação Estatística. REnCiMa, 9(2), 127-146.

Souza, A. C. S.; Souza, L. O.; Mendonça, L. O.; Lopes, C. E. (2013). O Ensino de Estatística e Probabilidade na Educação Básica: atividades e projetos gerados a partir de pesquisas de Mestrado Profissional. Vidya, 33(1), 49-65, jan./jun., Santa Maria.

Perin, A. P.; Wodewotzki, M. L. L. (2018). Contribuições da Modelagem Matemática para o Desenvolvimento da Literacia Estatística: uma experiência em um curso superior tecnológico. In Anais do $7^{a}$ Seminário Internacional de Pesquisa em Educação Matemática da SBEM. Foz do Iguaçu, PR. Recuperado de http://www.sbemparana.com.br/eventos/index.php/SIPEM/VII_SIPEM/paper/view/393/2 74

Submetido em: 30/03/2019

Aceito em: 07/09/2019 